\title{
Title of the Article: Paranasal Mucormycosis in COVID-19 Patient
}

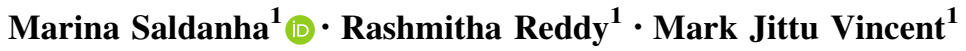

Received: 6 February 2021/Accepted: 17 April 2021/Published online: 22 April 2021

(C) Association of Otolaryngologists of India 2021

\begin{abstract}
There have been a variety of complications reported during and post- COVID infection. Recently, there has been an increase in sporadic cases of paranasal sinus mucormycosis in COVID- 19 patients. We report a case of COVID- 19 patient diagnosed to have orbital apex syndrome secondary to mucormycosis of nose and paranasal sinus requiring emergency endoscopic sinus surgery. Appropriate use of personal protective equipment and safety precautions taken by health care workers prevented the spread of the virus during surgery.
\end{abstract}

Keywords COVID-19 - Mucormycosis .

Orbital apex syndrome

\section{Introduction}

Coronavirus disease 2019 (COVID-19) is an infectious disease caused by newly discovered novel severe acute respiratory syndrome Coronavirus 2 (SARS-CoV-2), affecting more than 10 million people worldwide. There have been a variety of complications reported during and post COVID infection [1]. Sporadic reports of mucormycosis in COVID-19 patients have been documented. We

Marina Saldanha

saldanhamarina@gmail.com

Rashmitha Reddy

rashmireddyk.rr@gmail.com

Mark Jittu Vincent

jittu1992@gmail.com

1 Department of Otorhinolaryngology and Head and Neck Surgery, K.S.Hegde Medical Academy, NITTE University, Mangalore, Karnataka 575018, India report a case of a COVID -19 patient diagnosed to have orbital apex syndrome secondary to mucormycosis of nasal and paranasal sinus requiring emergency endoscopic sinus surgery.

\section{Case history}

A 32 year old lady with uncontrolled diabetes since six months presented with left eye complete ptosis and left facial pain since 5 days. On ophthalmic evaluation her visual acuity in left eye was $6 / 36$, pupil was $4 \mathrm{~mm}$ dilated and fixed, not reacting to light and extraocular movements were restricted. Right eye was normal. She was referred to Department of Otorhinolaryngology for evaluation. Nasal endoscopy was done and she had deviated nasal septum to the right with spur. Pus was visualized in the left middle meatal region and swab was sent for culture and sensitivity. On radiological evaluation, CT scan nose and Paranasal sinus showed near total opacification of the left ethmoid, maxillary and frontal sinus suggestive of fungal sinusitis. Thickening of the left optic nerve with perineural fat stranding was also noted [Fig.1]. MRI Brain was also done and showed peripherally enhancing subperiosteal lesion in the superomedial extraconal aspect of the left orbit which was suggestive of subperiosteal abscess with optic neuritis secondary to sinusitis [Fig.2]. She was planned for emergency endoscopic surgery with or without debridement. Cartridge-based nucleic acid amplification test (CBNAAT) for COVID-19 was done on an emergency basis and her report came as Covid positive. In view of impending orbital apex syndrome and the surgery falling in Group A [2] classification of endonasal surgery during covid pandemic, endoscopic sinus surgery was planned with adequate precautions. The surgical steps during surgery 
Fig. 1 CT scan showing total opacification of left frontal, ethmoid and maxillary sinus

Fig. 2 MRI scan peripherally enhancing subperiosteal lesion in the superomedial extraconal aspect of the left orbit
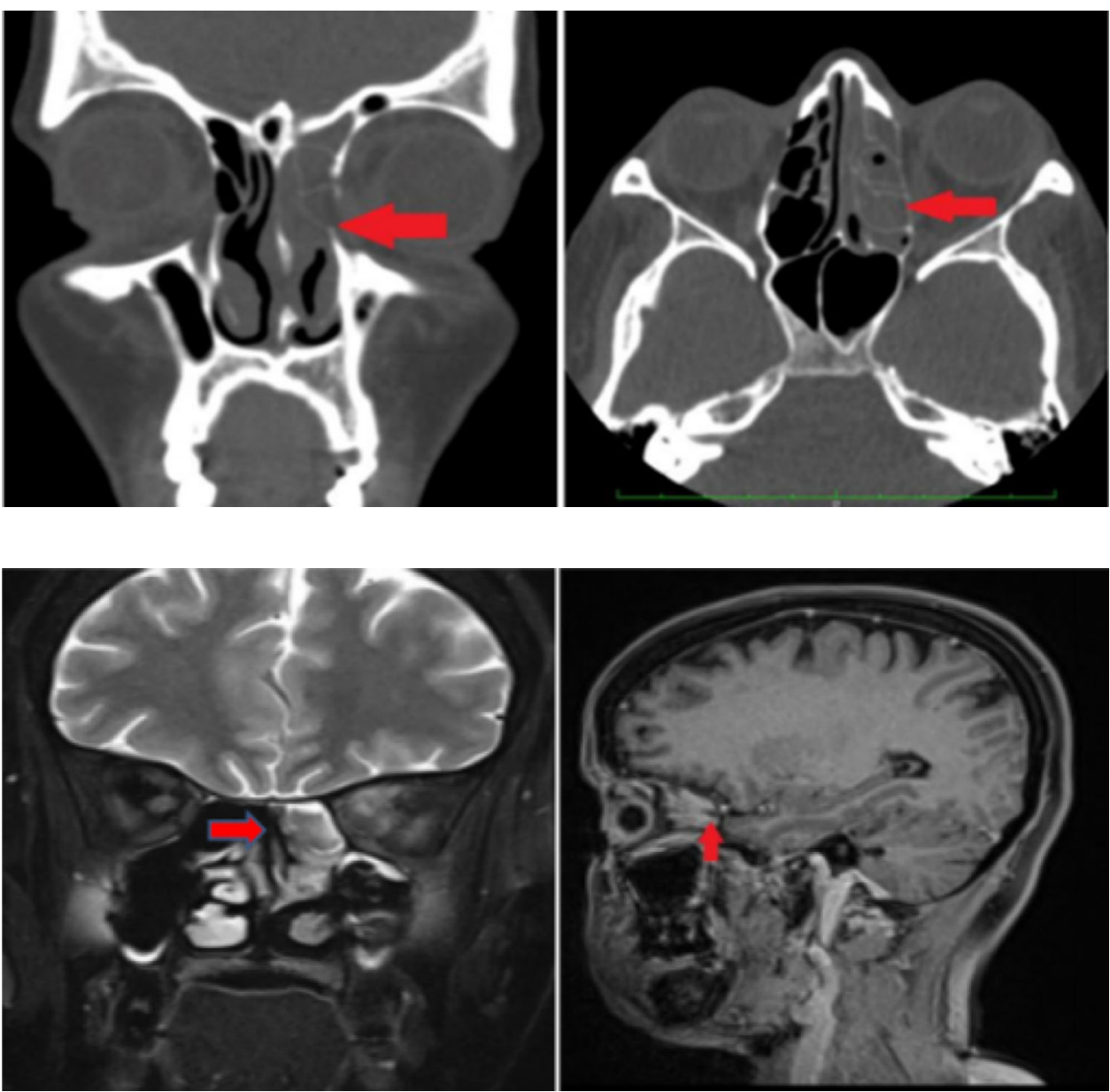

remained the same.The following precautions were taken during surgery -

1. The surgical and anesthesia team wore Personal protective equipment (PPE), surgical cap, N-95 mask, hood and double gloves.

2. Pre-operatively betadine $(0.5 \%)$ drops [3] were instilled in each nostril of patient half an hour before procedure and after induction on the operative table.

3. Surgical tent was created and secured by using barrier draping technique [4]. Three out pouches were created in drape - two for surgeon's hand, and the third opening was for suction, camera and light carrier [Fig.3].

4. Strict donning and doffing measures were followed.

Tissue was sent for histopathological examination and $\mathrm{KOH}$ mount which confirmed mucormycosis. She was started on conventional Amphotericin B $25 \mathrm{mg} /$ day. Her repeat RT PCT after fourteen days came positive and was discharged at request due to financial constraints. Her further follow up for two months were through telephonic interview. She reported reduction of facial pain and improvement in lagophthalmos but no improvement in vision.

\section{Discussion}

Mucormycosis is a serious but rare opportunistic fungal infection, mainly affecting elderly diabetic, immunocompromised individuals and spreads rapidly causing infarction and necrosis in the host tissue [1]. Rhino-orbital- cerebral infection is the most typical presentation of mucormycosis where there is an invasion of the fungal infection from paranasal sinuses to orbit and brain [5, 6]. Orbital apex syndrome is a rare manifestation of invasive mucormycosis [7]. This condition is often fatal, which leads to complete ophthalmoplegia with rapid vision loss, involving cranial nerves II, III, IV, V, and VI [8] requiring immediate treatment with anti-fungal, surgical intervention and control of risk factors to prevent morbidity [9]. During the advent of novel coronavirus disease, the prevalence of paranasal mucormycosis is on the rise, probably due to systemic immune alterations due to Coronavirus infection [10]. Alternations in innate immunity associated with 
Fig. 3 The figure shows the barrier draping method with three ports
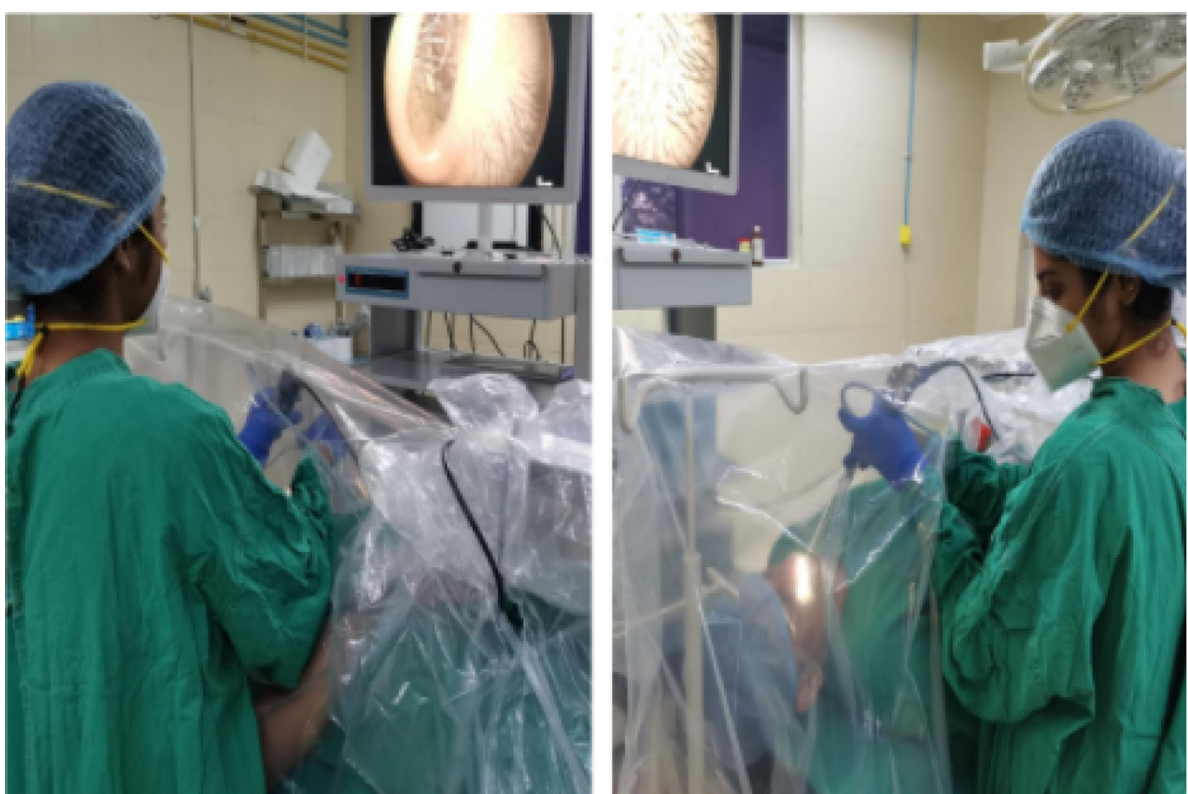

COVID-19 may be due to reduced number of T lymphocytes, CD4 + T, and CD8 + T cells [11]. The patient we described with orbital apex syndrome secondary to paranasal mucormycosis was positive for Coronavirus infection requiring emergency endoscopic sinus surgery with debridement. As endoscopic sinus surgery is an aerosolgenerating procedure and there is a high risk of transmission of corona virus, precautions were taken during surgery. There were no changes in the technique of endoscopic sinus surgery. At times the surgeon experienced difficulty in maneuvering in the tent. The overall operation time increased due to the setting up of the drapes and precautions taken during intubation and extubation.

As per literature, few cases of secondary mucormycosis have been reported previously [10]. Hanley et al. reported a case of 22 years old male with COVID- 19 pneumonia in whom disseminated mucormycosis involving the lungs and brain was incidentally discovered during a post-mortem study [12].

We observed that by following adequate precautionary measures in the operating room and by using barrier drapes the operating team and operation theatre personnel, no one had contracted the virus.

\section{Conclusion}

The need of immediate intervention in our patient was identified, relevant precautions during surgery on a COVID-19 patient were taken and all the health care workers were safe even after four weeks of exposure.

Safety of the health care workers along with complete patient care is the need of the hour in emergency interventions in cases of COVID-19 which can be managed successfully with adequate precautions.

Funding The authors received no financial support for the research, authorship and/or publication of this article.

\section{Declarations}

Conflicts of interest None.

\section{References}

1. Werthman-Ehrenreich A (2020) Mucormycosis with orbital compartment syndrome in a patient with COVID-19. Am J Emerg Med S0735-6757(20):30826-30833. https://doi.org/10.1016/j.ajem.2020.09.032

2. Radulesco T, Verillaud B, Béquignon E et al (2020) COVID-19 and Rhinology, from the consultation room to the operating theatre. Eur Ann Otorhinolaryngol Head Neck Dis 137(4):309-314

3. Khan MM, Parab SR (2020) $0.5 \%$ povidone iodine irrigation in otorhinolaryngology surgical practice during COVID 19 pandemic. Am J Otolaryngol. 41(6):102687

4. Tsagkovits A, Ioannidis D, Rokade A (2021) The microscope drape method to reduce aerosolisation during endoscopic sinus and skull base surgery in the COVID era. How i do it. Eur Arch Otorhinolaryngol. 278(2):573-6

5. Garlapati K, Chavva S, Vaddeswarupu RM, Surampudi J (2014) Fulminant mucormycosis involving paranasal sinuses: a rare case report. Case Rep Dent 2014:465919

6. Ferguson BJ (2000) Mucormycosis of the nose and paranasal sinuses. Otolaryngol Clin North Am 33(2):349-365

7. Quah WJ, Gunavathy M (2018) Orbital apex syndrome: an unusual complication of invasive mucormycosis. Proc Singap Health 27(4):287-289 
8. Anders UM, Taylor EJ, Martel JR, Martel JB (2015) Acute orbital apex syndrome and rhino-orbito-cerebral mucormycosis. Int Med Case Rep J 8:93-96

9. Kermani W, Bouttay R, Belcadhi M, Zaghouani H, Ben Ali M, Abdelkéfi M (2016) ENT mucormycosis. Report of 4 cases. Eur Ann Otorhinolaryngol Head Neck Dis. 133(2):83-6

10. Mehta S, Pandey A (2020) Rhino-orbital mucormycosis associated with COVID-19. Cureus 12(9):e10726

11. Gangneux JP, Bougnoux ME, Dannaoui E, Cornet M, Zahar JR (2020) Invasive fungal diseases during COVID-19: we should be prepared. J Mycol Med 30:100971
12. Hanley B, Naresh KN, Roufosse C, Nicholson AG, Weir J, Cooke GS, Thursz M, Manousou P, Corbett R, Goldin R, Al-Sarraj S, Abdolrasouli A, Swann OC, Baillon L, Penn R, Barclay WS, Viola P, Osborn M (2020) Histopathological findings and viral tropism in UK patients with severe fatal COVID-19: a postmortem study. Lancet Microbe 1(6):e245-e253. https://doi.org/10.1016/S2666-5247(20)30115-4

Publisher's Note Springer Nature remains neutral with regard to jurisdictional claims in published maps and institutional affiliations. 